\title{
LITERATUROZNAWSTWO
}

Татьяна Автухович

DOI 10.15290/sw.2019.19.01

Гродненский государственный университет имени Янки Купалы

Филологический факультет

Кафедра русской филологии

tel.: +375 297830943

e-mail: avtuchovich@mail.ru

ORCID ID: https://orcid.org/0000-0001-9640-8673

\section{Миф как пространство индивидуально-творческой интерпретации}

Ключевые слова: миф об Адонисе, редукция мифа, интерпретация, Борис Пастернак, Иосиф Бродский

Заявленная в заглавии статьи проблема будет рассмотрена на примере интерпретации мифа об Адонисе Борисом Пастернаком и Иосифом Бродским. Сопоставление поэтов может показаться странным. С одной стороны, известно, что отношение Бродского к Пастернаку было уважительно-доброжелательным и внимательно-заинтересованным: сохранилась видеозапись, на которой он читает стихи Пастернака; исследователи находят множество микроцитат, реминисценций, случайных и неслучайных совпадений, перекличек на уровне образов, рифм, даже сюжетов в их творчестве, которые свидетельствуют об интертекстуальном диалоге Бродского с Пастернаком [Ранчин]. Большая исследовательская литература посвящена интерпретации поэтического диалога Бродского с Пастернаком в стихотворениях с одинаковым названием Рождественская звезда (стихотворение Пастернака написано в 1947 г., Бродского - в 1987 г.).

С другой стороны, известно, что Пастернак не входил в число любимых авторов Бродского: например, в Нобелевской лекции (1987) он не включил его в число поэтов XX века, тени которых постоянно его смущают, - таковыми для него были Мандельштам, Цветаева, 
Роберт Фрост, Ахматова и Уистен Оден [Бродский 2001, I, 5]. Более того, как пишет Аркадий Ранчин, «из так называемой "большой четверки" русских поэтов постсимволистской эпохи (Анна Ахматова, О.Э. Мандельштам, Б.Л. Пастернак, М.И. Цветаева) автор Cестрьи моей - жизни и Стихотворений Юрия Живаго, как свидетельствуют эссе и интервью Бродского, был ему наименее близок. Бродский, хотя и называл среди наиболее значимых для своего поколения имя Пастернака ${ }^{1}$, не посвятил ему ни эссе, ни доклада, ни обстоятельного интервью и упоминал достаточно редко. В этом - разительное отличие от отношения к Ахматовой и Цветаевой, о которых Бродский писал и говорил много и очень личностно, и от Мандельштама, чье имя не столь часто в его интервью, но кому посвящены два эссе» [Ранчин]. По Ранчину, подобное отношение Бродского к Пастернаку было обусловлено идеологическим неприятием («Пастернак - единственный из "большой четверки", кто почти до самой смерти умел более-менее удачно вести диалог с глубоко антипатичной Бродскому советской властью» $[\mathrm{Pан-}$ чин]) и мировоззренческим несовпадением: радостному и благодарному приятию мира, пастернаковской причастности бытию противостоит отчужденность от бытия и трагическое восприятие мира у Бродского. И даже в тех случаях, когда, как показал А. Ранчин, Бродский цитирует Пастернака или вступает с ним в поэтический диалог, он «переписывает» его, вкладывает в пастернаковские мотивы «обратный смысл» [Ранчин 2001, 76].

Эта противоположность проявляется и в эпизоде, о котором пойдет речь в данной статье: Пастернак и Бродский в разное время независимо друг от друга обратились в своих стихотворениях к одному и тому же мифу, но актуализировали разные его элементы, которые, попав в контекст разных творческих интерпретаций, настолько видоизменились, что ситуация непрямого диалога поэтов через миф осталась неопознанной и не была отмечена исследователями. Однако цель данной статьи не в том, чтобы в очередной раз продемонстрировать отличие творческих установок Бродского и Пастернака или доказать факт полемики младшего поэта со старшим, а в том, чтобы показать безграничный интерпретативный потенциал мифа и изменение принципов работы поэтов с мифом на протяжении $\mathrm{XX}$ века.

1 В примечаниях к статье Аркадий Ранчин приводит слова Бродского из интервью Соломону Волкову: «Эти люди нас просто создали. И все. Вот что их делает нашими современниками. Ничто так нас не сформировало - меня, по крайней мере, - как Фрост, Цветаева, Кавафис, Рильке, Ахматова, Пастернак» [Волков 1998, 45]. Имя Пастернака в этом интервью названо последним. 
Итак, Борис Пастернак в стихотворении Tbl в ветре, веткой пробующем (1919) и Иосиф Бродский в стихотворении Иллюстраиия (Л. Кранах «Венера с яблоками») (1964) обратились к греческому мифу об Адонисе - божестве «с ярко выраженными растительными функциями, связанными с периодическим умиранием и возрождением природы» [Тахо-Годи 2000, 46]. Известно множество версий мифа. Общим в них является то, что Адонис - сын Феникса и Алфесибеи, отца и дочери, - был настолько красив, что богиня любви Афродита влюбилась в него, но владычица подземного царства Персефона, которой он ребенком был отдан на воспитание, не хотела отпускать его из своих владений. Зевс приказал Адонису часть года проводить на земле с Афродитой, а вторую часть под землей с Персефоной. Но информация о причинах смерти Адониса вариативна. По одной версии, разгневанная оказанным Афродите предпочтением Артемида посылает на юношу дикого кабана - вепря, который смертельно ранит его, ударив клыком в бедро. Согласно другим вариантам, Адонис стал жертвой 1) гнева Аполлона, который таким образом отомстил Афродите за ослепленного ею сына, 2) ревнивого любовника богини Ареса - именно он превратился в вепря, 3) мести отвергнутой им Персефоны. Во всех версиях присутствует инвариантный мотив - ревности и мести, отличаются «заказчики» и/или исполнители. Различаются и варианты посмертного чуда, совершенного Афродитой, которая горько оплакивает Адониса: по одной версии, по воле Афродиты Адонис вернулся из подземного царства и был превращён ею в цветок анемон. В другом варианте из пролитой крови Адониса расцвели розы, а из слез Афродиты - анемоны [Тахо-Годи 2000, 46-49].

Миф породил богатую символику. Так, анемон в античной культуре символизирует печаль, скорбь, смерть, а также кровь Адониса. В христианской культуре анемоны, впервые выросшие на Голгофе в момент Распятия Христа, - символ страдания: красные пятнышки на цветке символизируют кровь Христа и мучеников, тройной лист Троицу; анемон изображали в сценах Распятия и оплакивания Марией Христа [Анемон].

Прежде чем перейти к интерпретации мифа об Адонисе в стихах Пастернака и Бродского, обозначим теоретические положения, которые объясняют способность мифа порождать бесчисленные варианты переосмысления и истолкования. Борис Путилов писал о мифе и его жизни в культуре: «Однажды возникнув в глубинах истории, сюжет живет через закономерное варьирование его слагаемых и пересемантизацию 
его опорных пунктов при одновременном сохранении их инвариантных значений» [Путилов 1994, 178].

Миф представляет собой архетип и выступает как своеобразный шифр, ключ к которому кроется в образе главного героя. Смысл, закодированный в имени, «разворачивается» в мифе до целого сюжета как «отражения динамики действительности в форме развертывающегося (...) действия» [Михайлов, Михайловский 1939, 150]. Именно поэтому Ольга Фрейденберг называла миф «транскрипцией в слове представлений», при этом мифологический сюжет представляет собой «систему развернутых в словесное действие метафор; вся суть в том, что эти метафоры являются системой иносказаний основного образа» [Фрейденберг 1997, 223]. Метафора, «называя предметы не своими собственными именами, а именами других вещей, обнаруживает в каждом явлении присутствие множества различных смыслов и ставит под сомнение тождественность вещей самим себе» [Полозова 2004, 73]. В этой связи важным представляется замечание Якова Голосовкера о том, что «каждый миф дает нам тот или иной единичный конкретный образ и смысл этого образа. (...) Совокупность таких конкретных образов, представленных в плане одного развивающегося смысла, (...) составляет “целокупный образ" группы мифов» [Голосовкер 2010, 141]. При этом в мифе наблюдается логически последовательное развитие смысла целокупного образа до его полного исчерпывания. Важную роль в структуре мифологического сюжета играют бинарные оппозиции, которые придают ему амбивалентность и семантическую многоплановость, - именно амбивалентность и многоплановость семантики, наряду со свернутым в «заглавном» образе смыслом, обеспечивают мифу долгую жизнь в культуре. Концентрируя в конкретно-чувственной форме знание о важнейших аспектах бытия, миф становится неотьемлемой частью ментальной сферы представителей одного культурного пространства.

В мифе об Адонисе в качестве главных смыслообразующих оппозиций выступают жизнь/смерть, смерть/возрождение, любовь/смерть, любовь/ревность, любовь/месть, жертва/печаль. Символический потенциал присущ не только образу Адониса, но и метафорическим составляющим мифологического сюжета - анемонам, выросшим из слез Афродиты, крови убитого бога, вепрю - воплощению неоправданной жестокости на почве мести.

Сюжет мифа об Адонисе пользовался большой популярностью и нашел отражение в мировой живописи (Джорджоне, Тициан, Тинторетто, Веронезе, Рубенс, Пуссен), скульптуре (Канова, Торвальдсен, Ро- 
ден), музыке (оперы Монтеверди, Р. Камбера, Р. Кайзера) и литературе. Как показал Александр Житенев, сюжет об Адонисе был популярен в поэзии Серебряного века [Житенев 2018]. На рубеже XIX-XX веков большую популярность приобрел художник Вильгельм Котарбинский, который синтезировал черты салонной культуры и модернизма, среди его произведений - картина $A$ немоньl, многократно тиражированная на почтовых открытках.

Нельзя не заметить, что способы бытования сюжета в культуре менялись со временем. Так, в эпоху рефлективного традиционализма - вплоть до конца XVIII века миф выступал в качестве готового (вечного) сюжета и, как правило, был для автора объектом инвенции - риторической разработки: в произведениях перечисленных выше художников варьируется изображение любовных отношений между Адонисом и Афродитой, закономерно, что уже в XIX веке сюжет становится объектом внимания скульпторов, для которых на первом месте оказывается не «изобретение» композиции, а пластическое выражение сути. Это означает, что в эпоху креативизма миф становится объектом индивидуально-творческого переосмысления, кроме того, на протяжении XIX-XX вв. происходит постепенная редукция и даже разрушение целостного сюжета: миф распадается на свои составляющие, которые представительствуют за целое и могут вступать во взаимодействие с элементами других мифов в рамках авторского замысла. В этом суть модернистского неомифологизма. Параллельно происходит перемещение сюжета в массовое искусство, пример чему - Анемоны Котарбинского, где миф выводится за пределы изображения и только угадывается в названии картины. На рубеже XX-XXI вв. осколки мифологических сюжетов функционируют в культуре в качестве «готового слова», эмблем, отсылающих к архетипическому сюжету и стоящему за ним смыслу, но зачастую не опознаваемых в таком качестве, поскольку выявление мифологической «родословной» и соответствующих подтекстов невозможно без читательской интуиции и герменевтического усилия. При этом в составе нового художественного целого метафорический образ чаще всего опредмечивается и воспринимается в его буквальном значении.

Обратимся к произведениям Б. Пастернака и И. Бродского.

Пастернак в стихотворении Tы в ветре, веткой пробующем... обращается к мифу об Адонисе, но актуализирует не весь сюжет, а только самый знаковый его образ - анемона. 
Ты в ветре, веткой пробующем,

Не время ль птицам петь,

Намокшая воробышком

Сиреневая ветвь!

У капель - тяжесть запонок,

И сад слепит, как плес,

Обрызганный, закапанный

Мильоном синих слез.

Моей тоскою вынянчен

И от тебя в шипах,

Он ожил ночью нынешней,

Забормотал, запах.

Всю ночь в окошко торкался,

И ставень дребезжал.

Вдруг дух сырой прогорклости

По платью пробежал.

Разбужен чудным перечнем

Тех прозвищ и времен,

Обводит день теперешний

Глазами анемон [Пастернак 1989, 118].

В контексте стихотворения, в котором описываются летний сад после ночного дождя, анемон воспринимается в своем предметном значении - как растение, цветок. Именно как деталь предметного мира воспринял данный образ Борис Бухштаб - автор проницательной статьи о поэтике Пастернака, на которую обратил внимание сам поэт, попросив Ольгу Фрейденберг передать ему экземпляр ленинградской «Красной газеты», где 10 февраля 1928 г. она была напечатана [Пастернак 1987,106$]$. Рассуждая о конкретности и точности поэтической детали в стихах Пастернака, исследователь выделяет «принцип предельной дифференциации имен»: «Для Пастернака нет, скажем, "цветов" или "растений" вообще; есть астры, делии, флоксы, гиацинты, олеандры, анемоны (...) Кажется, что все предметы мира настолько индивидуально знакомы поэту, что для него уже неважны их родовые черты, и он жалеет, что не может назвать каждый предмет особым именем» [Бухштаб 1987, 111]. В приведенном Бухштабом перечне выделяется анемон как не самый характерный для русской садовой культуры цветок, однако автор статьи не замечает этого. Только позднейшие исследования показали наличие мифопоэтического начала в книге Сестра моя - жизнь. Лето 1917 года, в которую входит стихотворение: мир предстает перед поэтом как феномен космогонии - посто- 
янного рождения и обновления, что предполагает актуализацию мифологических подтекстов в используемых предметных образах или их индивидуальную мифологизацию.

Стихотворение Tbl в ветре, веткой пробующем входит в открывающий книгу цикл Не время ль птииам петь, в котором заявлены ее основные тематические мотивы - творчество, любовь, время. Цепь метафорических образов представляет собой пучок ассоциативных определений неназванного «Ты», к которому обращается поэт ( $\mathrm{Tbl}$ в вет$\kappa e$, от тебя в слезах) и в котором все названные темы объединяются в ключевом для книги понятии ЖКизнь. «Лирический сюжет книги - узнавание жизни как откровения любви» [Брюханова 2010, 27], но в анализируемом стихотворении это узнавание сопряжено со страданием, тоской, тревогой (отсюда микромотивы сад, (..) обрызганныии, закапанньй / мильоном синих слез, моей тоскою вьнянчен / и от тебя в шипаx), пониманием жизни как вечного обновления (сад ожил ночью ньюнешней, но при этом вдруг дух сьърой прогорклости / По платью пробежал, что можно понять как знак присутствия смерти). Все эти мотивы в стихотворении актуализируют символические значения образа анемона и подготавливают его появление в заключительной строфе. При этом нельзя не обратить внимание на оформление этого события: анемон разбужен, он разбужен чудным перечнем / Тех прозвищ u времен - глагол несет семантику не только весеннего возрождения природы, но и припоминания лирическим героем культурных смыслов, с которыми связан анемон. Другими словами, анемон является не только референтным феноменом природного мира и фактом культуры (отметим в скобках, что Пастернак опирается не только на античный миф, но и на литературную традицию его истолкования в поэзии Серебряного века, «сворачивая» эту традицию до уровня знакового образа), но и порождением творимой на глазах читателя поэтической вселенной Пастернака. Именно поэт вызывает к жизни («пробуждает») ассоциативный метафорический потенциал образа, подчеркивая в нем традиционные смыслы и обогащая их новыми контекстами.

Важно при этом, что упоминание об анемоне актуализирует и собственно миф об Адонисе, прежде всего его любовную линию, подготавливая таким образом появление любовного сюжета в книге, а неартикулируемое имя бога Адониса косвенно характеризует и самого автора, который в своей книге предстает как создатель поэтической вселенной. Можно сделать вывод, что у Пастернака знаковая деталь мифа об Адонисе не только метонимически замещает весь миф, но и включается в создание собственного авторского мифа. При этом в контексте обще- 
го замысла книги и целостности авторской космогонии мотивы тоски, печали, страдания, связанные с образом анемона, переосмысливаются: актуализируется семантика возрождения, изначально заложенная в мифе.

Обратимся к стихотворению Бродского.

В накидке лисьей - сама

хитрей, чем лиса с холма

лесного, что вдалеке

склон полощет в реке,

сбежав из рощи, где бог

охотясь вонзает в бок

вепрю жало стрелы,

где бушуют стволы,

покинув знакомый мыс,

пришла под яблоню из

пятнадцати яблок - к ним

с мальчуганом своим.

Головку набок склоня,

как бы мимо меня,

ребенок, сжимая плод,

тоже смотрит вперед [Бродский 2001, II, 26].

Название стихотворения - Иллюстрация (Л. Кранах «Венера с яблоками») ориентирует на его восприятие как экфрасиса картины Лукаса Кранаха Старшего Мадонна с младенчем под яблоней (1526). Однако при внимательном прочтении нельзя не заметить, что Бродский изменил название картины немецкого художника, редуцировал одни детали, добавил другие и в результате создал герметичный текст с многоуровневой перспективой понимания: автобиографическая ситуация (измена возлюбленной поэта М.Б. с его другом) включается в разнонаправленный диалог с культурой, в том числе с картиной Кранаха, и целью этого диалога для Бродского оказывается отнюдь не истолкование замысла живописца, а решение нравственно-философских проблем, связанных с отношением к греху.

Подробный анализ образной системы стихотворения Бродского и его интерпретация даны в моей статье [Автухович 2016], поэтому здесь приведем только значимые для интересующей нас в данном случае проблемы тезисы. Герметичность текста во многом обусловлена тем, что Бродский сопрягает в стихотворении античные и библейские образы и реминисценции, и это порождает ситуацию эпистемологической неуверенности для читателя, который вынужден ответить на 
цепь взаимосвязанных вопросов: почему поэт изменил название картины Кранаха, заменил Мадонну на Венеру? Почему не упоминает про хлеб в руке Младенца? Почему акцентирует такую деталь, как яблоки и их количество? Почему в связи с рыжими волосами Венеры вводит мотив лисьей хитрости героини? Наконец, почему во второй строфе развивает целый микросюжет, отсутствующий на картине Кранаха, словно разворачивая свернутый и невидимый на статичном полотне нарратив?

Отвечая кратко на эти вопросы, можно сказать, что Бродский восстанавливает античные соответствия христианской символики, которая доминирует в картине Кранаха. В результате появляется перспектива экзегетического истолкования каждого образа - в парадигме античного мифа и христианской символики. Смысл такого соположения видится в том, что мифологический образ, в отличие от христианского символа, отличается большей семантической амбивалентностью и способен порождать цепочки разнонаправленных ассоциаций и соответственно истолкований. Благодаря этому, осмысливая свою драму, Бродский идет от однозначности идеи христианского искупления и всепрощения к признанию неоднозначности всех проявлений человеческой натуры: амбивалентность мифа предполагает диалектичную двойственность оценки явления и открывает для поэта возможность более широкой гуманистической позиции.

Так, Бродский актуализирует в стихотворении не образ Евы, с которым в экзегетической традиции связан образ Марии, а образ Венеры: Ева совершила грех по неведению, Венера же в мифологии выступает как воплощение изначальной раздвоенности - склонности к греху и способности к духовному преодолению своей сущности. В данном случае значимым в тексте оказывается мотив бегства Венеры: сбежав из рощи, (...) где бушуют cmвольл, она приходит под яблоню из пятнадцати яблок. Мотив бегства соотносится с характерным сказочным сюжетом, когда принцесса блуждает по лесу, чтобы затем выйти к замку=спасению; акцент на стволах деревьев отсылает к семантике мирового древа, у которого именно ствол=тело связан с земным миром (землей) и человеком; фраза бушуют cmвольл, надо полагать, характеризует пространство, из которого бежит Венера, как пространство телесных, земных радостей, на такую же семантику нацеливает и «роща», которая в культуре выступает как один из вариантов locus amoenus - «приятного места», сада земных наслаждений. В свою очередь пятнадцать яблок на яблоне, к которым пришла героиня с младенцем (пришла под яблоню из / пятнадиати яблок-к ним / с мальчуганом 
своим; выделено мной. - T.A.), отсылают к христианской символике числа, в том числе к пятнадцати ступеням восхождения по «духовной лествице» как пути искупления греха и обретения спасения.

Какую же роль в этом подтекстовом нарративе, восстанавливаемом благодаря актуализации мифологических значений, играет образ вепря? Во-первых, в мифологии вепрь обладает амбивалентными характеристиками: ему присущи плодородие, сила, бесстрашие и в то же время дикость, безнравственность, вредоносность. Однако для нас важно, и это во-вторых, что образ вепря связан с мифом об Адонисе, хотя и находится в нем на периферии сюжета. С мифом об Адонисе в свою очередь связан образ Венеры, которая выступает коррелятом Афродиты, - использование двух персонажей одного мифа в стихотворении Бродского указывает на присутствие данного сюжета в сознании поэта в момент работы над стихотворением. В проекции иносказательного смысла стихотворения на биографический контекст можно предположить, что Бродский актуализирует мотив ревности и мести, связанный с образом вепря; акцентирует мотив ухода Венеры-Афродиты и «проигрывает» возможный вариант наказания свыше вепрю, нанесшему (метафорическую) смертельную рану лирическому герою. Возможна и другая интерпретация: с мстительным вепрем Бродский сравнивает себя, в то время как богом, который вонзает в его тело стрелу, может быть Купидон. Изначальная амбивалентность образов допускает разные истолкования вставного сюжета.

Можно говорить о том, что Бродский, внеся в свой экфрасис отсутствующий на картине Кранаха микросюжет, развернул в нарратив тот символический смысл, который имплицитно подразумевается в образе Девы Марии, искупающей первородный грех Евы. В проекции на биографический контекст представленная в экфрасисе Бродского интерпретация картины Кранаха отражает его глубокое и отнюдь не ригористическое понимание женской сущности и в целом категории греха. Возможно, такая процессуальность, оправдывая героиню, которая проходит путь от Венеры до Мадонны, воплощает в тексте надежду автора на примирение с возлюбленной.

Безусловно, смысл второй строфы в контексте художественного целого стихотворения и его биографического контекста может интерпретироваться по-разному. Для нас в данном случае важно другое: античный сюжет в стихотворении Бродского в еще большей степени редуцирован и представлен периферийным образом, а также образом-коррелятом; Бродский подключает сюжет об Адонисе ко всему полю европейской культуры, с которой вступают в диалог и автор стихотво- 
рения, и собственно сам сюжет. Это означает, что в сознании поэта нет места пастернаковскому утверждению торжества жизни, неизбежности возрождения, - напротив, для Бродского характерна проблематизация всех традиционных истин и императивов, в том числе идеи христианского понимания греха и вины; античные и библейские мифы выступают для него только как достояние культуры и являются аргументами в процессе самопознания.

Таким образом, стихотворения Пастернака и Бродского, реминисцентное поле которых включает миф об Адонисе, демонстрируют процесс редукции мифа в литературе XX века, постепенного превращения его в «готовое» слово культуры. Модернизм как любая переходная эпоха осуществляет компрессию предшествующей культуры, переводя ее поиски и достижения в область «готового слова», и потому обращается к архетипическим образам, которые позволяют создать текст с неограниченным смысловым потенциалом. И Пастернак, и Бродский используют знаковые образы мифа для визуализации смысла, который таким образом уходит в подтекст, выражается имплицитно. Модернистская поэзия направлена на индивидуально-личностное осмысление мифологических образов и со-творение на этой основе каждым художником собственного духовного космоса (смысла). В то же время в пространстве индивидуального творчества происходит ремифологизация образа и, как следствие, сакрализация авторского внутреннего пространства.

\section{Литература}

Avtuhovič T., 2016. Èkfrasis kak metafora: Puti istolkovaniâ, [w:] Avtuhovič T., «Šag v storonu ot sobstvennogo tela...». Ėkfrasisy Iosifa Brodskogo», Siedlce, s. 59-75. [Автухович Т., 2016, Экфрасис как метафора: Пути истолкования, [в:] Автухович Т., «Шаг в сторону от собственного тела...». Экфрасисьи Иосифа Бродского», Siedlce, с. 59-75.]

Anemon, [v:] Kratkaâ ènciklopediâ simvolov. V: http://www.symbolarium.ru/ index.php [Dostup 21 IX 2018] [Краткая энииклопедия символов. V: http: //www.symbolarium.ru/index.php [Доступ 21 IX 2018]

Brodskij I., 2001. Illûstraciâ (L. Kranah «Venera s âblokami»), [w:] Brodskij I., Sočineniâ Iosifa Brodskogo, Sankt-Peterburg, tom II, s. 26. [Бродский И., 2001. Иллюстрачия (Л. Кранах «Венера с яблоками»), [w:] Бродский И., Сочинения Иосифа Бродского, Санкт-Петербург, том II, с. 26.]

Brodskij I., 2001. Nobelevskaâ lekciâ, [w:] Brodskij I., Sočineniâ Iosifa Brodskogo. Sankt-Peterburg, tom I, s. 5-16. [Бродский И. 2001. Нобелевская лекиия, [w:] Бродский И., Сочинения Иосифа Бродского. Санкт-Петербург, том I, c. 5-16.] 
Brûhanova Û.M., 2010. Tvorčestvo Borisa Pasternaka kak hudožestvennaâ versiâ filosofii žizni Irkutsk [Брюханова Ю.М., 2010. Творчество Бориса Пастернака как художественная версия философии жизни, Иркутск]

Buhštab B. Â., 1987. Lirika Pasternaka, "Literaturnoe obozrenie" nr 9, s. 107-112. [Бухштаб Б.Я., 1987. Лирика Пастернака, "Литературное обозрение" nr 9 , c. $107-112$.

Volkov S., 1998. Dialogi s Iosifom Brodskim, Moskva. [Волков С., 1998. Диалоги с Иосифом Бродским, Москва.]

Golosovker Â.̇̀., 2010. Logika mifa, Moskva, Sankt-Peterburg [Голосовкер Я.Э., 2010. Логика мифа, Москва, Санкт-Петербург.]

Žitenev A. A., 2018. «Umiraûŝij Adonis» G. Sapgira v kontekste russkoj poèzii XX veka, [v:] Čelovek govorâŝij, pišuŝij, čitaûŝij v literature, čast' 1, Grodno, s. 20-33. [Житенев А. А., 2018. «Умирающий Адонис» Г. Сапгира в контексте русской поэзии XX века, [w:] Человек говорящий, пишуший, читающий в литературе, часть 1, Гродно, с. 20-33.]

Mihajlov P., Mihajlovskij B., 1939. Sûžet, [w:] Literaturnaâ ènciklopediâ, tom 11, Moskva, stb 140-151. [Михайлов П., Михайловский Б., 1939. Сюжет, [в:] Литературная энииклопедия, том 11, Москва, стб. 140-151.]

Pasternak B. L., 1989. Ty v vetre, vetkoj probuûŝem..., [w:] Pasternak B. L., Sobranie sočinenij, tom 1, Moskva, s. 118. [Пастернак Б. Л., 1989. Tbl в ветре, веткой пробующем..., [в:] Пастернак Б. Л., Собрание сочинений, том 1, Москва, с. 118.]

Pasternak E.B., 1987. Vstupitel'noe slovo k publikacii stat'i B.Â. Buhštaba «Lirika Pasternaka», [w:] Literaturnoe obozrenie, 1987, nr 9, s. 106-107. [Пастернак Е.Б. 1987. Вступительное слово $к$ публикации статьи Б.Я. Бухштаба «Лирика Пастернака», [в:] Литературное обозрение, 1987, nr 9, c. 106-107.]

Polozova I.V., 2004. Glubinnye osnovaniâ metafory, "Vestnik Moskovskogo universiteta". Seriâ 7, Filosofiâ nr 3, s. 70-85. [Полозова И.В., 2004. Глубинньле основания метафоры, "Вестник Московского университета". Серия 7, Философия nr 3, с. 70-85.]

Putilov B.N., 1994. Fol'klor i narodnaâ kul'tura, Sankt-Peterburg. [Путилов Б.Н., 1994. Фольклор и народная культура, Санкт-Петербург.]

Rančin A., 2001. «Na piru Mnemoziny». Interteksty Brodskogo. Moskva. [Рaнчин А., 2001. «На пиру Мнемозины». Интертексть Бродского. Москва.]

Rančin A.M. O pasternakovskom plaste v poèzii Iosifa Brodskogo: stihotvorenie «Prišla zima i vse, kto mog letet'...». V: https://www.portal-slovo.ru/philo logy/47461.php. [Dostup 20 IX 2018] [Ранчин A.M. О пастернаковском пласте в поэзии Иосифа Бродского: стихотворение «Пришла зима и все, кто мог лететь...». V: https://www.portal-slovo.ru/philology $/ 47$ 461.php. [Доступ 20 IX 2018]

Taho-Godi A.A., 2000. Adonis [w:] Mify narodov mira. Ènciklopediâ, tom 1, Moskva, s. 46-49. [Тахо-Годи А.А., 2000. Адонис [в:] Мифы народов мира. Энииклопедия, том 1, Москва, с. 46-49.] 
Frejdenberg O.M., 1997. Poètika sûžeta i žanra, Moskva. [Фрейденберг O.M., 1997. Поэтика сюжета и жанра, Москва.]

\title{
MYTH AS A SPACE OF INDIVIDUAL CREATIVE INTERPRETATION
}

\author{
S U M M A R Y
}

Key words: the myth of Adonis, the reduction of myth, interpretation, Boris Pasternak, Joseph Brodsky

The article on the example of poems by Boris Pasternak You in the wind, a branch sampling (1919) and Joseph Brodsky Illustration (L. Cranach's "Venus with Apple") (1964) discusses the changing of the use of myth in the poetry of the twentieth century. Both poets turned to the myth of Adonis, but in the Pasternak's poem myth presented by the image of an anemone, and in Brodsky's by the images of a boar and Venus. It is shown that the poems of Pasternak and Brodsky demonstrate the process of the reduction of myth in the literature of the twentieth century and its gradual transformation into "ready" word of the culture. Modernism as any transitional epoch carries out the compression of the preceding culture, translating her quest and achievements in the area of "ready words", and therefore refers to the archetypal images that allow to create the text with unlimited semantic potential. Both Pasternak and Brodsky use the iconic images of myth to visualize the meaning, which thus leaves in the subtext and is expressed implicitly. Modernist poetry is aimed on the individual-personal interpretation of the mythological images and on the creation of the artist's own spiritual space. At the same time, the remythologization of the image and, as a consequence, the sacralization of the author's inner space takes the place. 